\title{
SOCIALLY INCLUSIVE AND ORIENTED TOWARDS THE PERSON EDUCATION FOR CHILDREN WITH CHRONIC DISEASES: IS THERE A HIDDEN DISCRIMINATORY PRACTICE?
}

\author{
E. Buyuklieva* \\ Faculty of Education, Trakia University, Stara Zagora, Bulgaria
}

\begin{abstract}
The report aims to indicate the specifics and peculiarities of children with chronic illnesses, who differ from those with learning disabilities and mental retardation. Children with chronic diseases may have cognitive impairments but they are not always caused by an intellectual deficit; rather, they are caused by complex factors. The existing special educational programs are designed for children with special educational needs - mainly with intellectual disabilities. These programs are still used for working with children with chronic diseases, which consequently creates problems with their social inclusion, their development and also problems for their families, the educators and society as a whole. The need for new research with the hypothesis that children with chronic diseases are entitled to education and training with specific training programs that prevent discriminatory practices arises not only because of the increase of the number of children with chronic disabilities, but also from the necessity for their adequate inclusion in the mainstream school environment. The report presents data and interpretation, which justifies the need for differentiated curricula that need to be worked out not only on the apart of the teachers - in their work of training and consulting, but also on the part of the parents and the medical professionals. Differentiated curricula are being defended on the basis of the holistic principle, so as to be constructive and antdiscriminatory in terms of children with chronic diseases, as well as children without such diseases. The report proclaims the modern idea of training and education together of children with and without chronic diseases.
\end{abstract}

Key words: discriminatory practice, chronic diseases, social inclusion, differentiated curriculum, holistic principle

\section{TERMINOLOGY USED IN THE REPORT}

According to the World Health Organization (WHO), a chronic disease (CD) is a permanent condition which can be controlled but not cured. This is a disease which accompanies a person throughout his or her life. Chronic diseases are long-term or permanent medical conditions that have either a continuous or a periodical impact on the daily lives of the patients and the relatives in their surroundings. Common chronic diseases include asthma, cancer, diabetes, eating disorders, sleep disorders, traumatic brain injury, epilepsy, and others. Less common, but no less serious in shape diseases include sickle cell anaemia, haemophilia, epilepsy and HIV/AIDS (1).

Chronical diseases have individual and social dimensions in society, both nationally and

\footnotetext{
*Correspondence to: Elena Buyuklieva, Faculty of Education, Trakia University - Stara, Zagora,

Bulgaria, eli@radio-sz.net
}

globally. When there is a CD in early childhood or from birth onwards, the individual and social dimensions of this fact are much more pronounced and visible (2).

With each passing year the number of children with chronic diseases is increasing not only in our country but around the world. But it is not only this growing number that raises concerns. Any $\mathrm{CD}$, except the typical picture of the chronic diseases, is characterized by specific symptoms and a clinical picture. Adding to the fact that family and school environment meet many difficulties in responding to the specific, not only physically, but primarily educational needs of children with $\mathrm{CD}$, the need for specialized support for these children, so that their rights are not violated and they do not appear to be discriminated against because of ignorance of those who take care of them, becomes quite understandable.

Educational needs of children with a CD differ in many ways from those of children with 
other disabilities. A CD can affect the energy and the concentration of the child, but this rarely affects one or another cognitive ability and the personal or general educational potential of the students with CD.

Although CDs are long-termed, they differ in their intensity. Some children can spend months or years in remission and episodic acute periods, others may be in almost constant activity or progression of the disease or a recovery. For most, the classroom in a mainstream school and the home or hospital opportunities are all that is necessary, but others need a full range of special educational programs and services.

Modern treatment and the related side effects differ from those of a decade ago. When new drugs and treatment regimens are available and implemented, children with chronic diseases are subject to unpredictable ups and downs. Metaphorically, it is like a roller coaster of changing needs, which is the difference between a $\mathrm{CD}$ and other disabilities.

\section{THE MAIN THESIS OF THE REPORT VS THE STEREOTYPE}

The main thesis of the report is related to the discriminatory assumption - the stereotype that the results of the schooling are determined solely by the medical indicators (3). To overcome this prejudice and, more importantly, to implement an effective prevention of this hidden discriminatory practice, it is necessary to change in principle the interpretation of the educational opportunities of children with CD. The broad effects of many chronic diseases can be solved by the medical professionals, school professionals and families of children with $\mathrm{CD}$, which are supposed to work as a team. Until now, knowing the medical information was not usually part of the curriculum for the training of teachers, psychologists, educators and others. The gap between vocational training and the need for knowledgeable professionals who can solve the medical problems is vast. Without changes and raising the qualification of the specialists, this difference is likely to grow and become larger.

Historically, in the past, the educational services for children with $\mathrm{CD}$ were developed so as to address the specifics of diseases such as polio and tuberculosis. In these services, which usually followed the medical model and were available in special schools and centres, students with a particular disease were separated from their peers. As the number of the cases of these diseases was reduced, the responsibility of the school became more diffuse. This model, however, has remained even today. Still, on the territory of our country, there are several remedial schools designed for children with heart and lung diseases.

Not very different from that is the picture until recently with the prejudices leading to a hidden discrimination against children and adolescents with $\mathrm{CD}$ in other countries. For example, T. Maues and his colleagues point out that, compared to children and adolescents with $\mathrm{CD}$, the relationship with the school, work, friends and family is disturbed, not because of the disease itself, but because of the lack of positive coping strategies. (4)

Before going to school, many children with $\mathrm{CD}$ from school age do not have a clue about their differences in relation to other children of the same age. At school they perceive that they are different, that often they take drugs which are in larger quantities than those that most of their classmates take. (5) In this age group, they perceive the physical differences and distinguish the deviations from "normal". Children considered "normal" show the shortcomings of others who are "different" from them, causing shame and constraints (6). When some problems arise, associated with the disease and treatment during childhood or adolescence, problems with the social adjustment are also expected. When children and adolescents with $\mathrm{CD}$ do not know the meaning of their disease and are "different" from the others, their acceptance by their peers is compromised (7).

Notwithstanding the individual events, the stigma and the discrimination are social constructs. Stigma is defined as "a property which is deeply disparaging and one that in the eyes of society discredits the person who possesses it". Stigmatized persons are considered as having an undesirable difference. Thus stigma manifests itself in society through differences, deviations. (8)

Discrimination is a consequence accompanying the stigma, and is expressed in the rejection of otherness, of difference. The psychological basis of discriminatory practices is the fear of the unknown and the different. Hence, it can be inferred that the main constructive strategy for the prevention of discrimination should focus on the knowledge and awareness of the differences. Discrimination, on the other hand, is an act of ethnocentrism in society and means that what is different is not liked (8). Hence, the "normality" looks like a strategy for coping with the stigma, to the extent that through 
actions people are trying to mitigate the difference and turn its existence closer to what is accepted as "normal" (9).

\section{Characteristics of the socio-educational problems of children with CD}

Some CDs and injuries lead to cognitive impairments of students. The social and educational development of children with CDs looks like a vicious circle: the disorders of cognition arise and at the same time there are also the consequences of the disease, the accompanying frustration and distress of the experience of "being doomed", as well as the drugs used to treat the disease. Many medications cause side effects that significantly affect learning, including: sedation, anxiety, irritability, lethargy, fatigue, difficulty in focusing, pain, nausea, emotional problems, tremors and poorly coordinated muscle movements. "The vicious circle" is expanded, as the cognitive difficulties and the problems with the behaviour of children with $\mathrm{CD}$ are accompanied by emotional and personal, social and behavioural problems, which in short can be expressed or summed up in two extremes - (self) isolation and / or hostility to others, including self-aggression.

Students may be hesitant to participate in activities with friends for physical reasons or because they feel too different or isolated. CD can prevent or hinder student participation in extracurricular activities that promote positive academic and social-emotional outcomes. Differences and restrictions can be particularly difficult for children and young people who feel under pressure, meeting the requirements for them. Frustration or exclusion may add mental health problems, which are connected essentially with the disease. Last but not least, some students with CD can suffer from lack of motivation and refuse to go to school. Refusal to attend school may be higher among students with CD (3).

Children who have a CD or some such condition, often feel "different", socially isolated and limited in their actions. They may have problems in school and feel the constant protection of their parents. It is possible for them to experience recurrent fear and pain. When these emotional difficulties are not controlled, they can lead to anxiety, sadness, withdrawal, rebellion or diminished interest in school. Social isolation experienced by students with $C D$ creates challenges for the social interaction when returning to school. School absences and discomfort are among the factors that exacerbate social exclusion. The constant struggle of a child with $\mathrm{CD}$, when trying to cope with lessons and tasks, adds a further social unrest. The psychological effects of CD makes students constantly compare themselves with their healthy peers. This creates a continuous feeling of imbalance in their abilities and difficulties, as noted by Wideman-Johnston et al (10).

Pao, M. \& Ludi, E stated that approximately $20 \%$ of children with CD have conditions of behavioural and emotional symptoms. These symptoms are a normal reaction, resulting from the disease and the hospitalization. But when they become intrusive and damaging to the child's development, it is needed to implement early intervention and even prevention. Symptoms of depression and anxiety, sleeplessness, loss of appetite and fatigue are common in chronically ill children. The presence of such symptoms can significantly affect the results in school. (11)

Sentenak and his colleagues (2011) found out that there is a significantly higher level of victimization among children with certain types of $\mathrm{CD}$, compared to healthy children. Victimization of children with $\mathrm{CD}$ is not rare and is associated with the appearance or behaviour, especially in children who have difficulty in developing relationships within the social networks. What follows from this is that children with $\mathrm{CD}$ are at a higher risk of harassment compared to their peers because of their manners, difficulties with mobility, their speech or the need for special care. (12)

Other research suggests that chronically ill children and adolescents do not necessarily have lower rates of social inclusion. However, the model of social participation, shown by people affected by $C D$, is different from that shown by people who are not affected. An interesting result was established by some studies, which at the same time directs towards common strategies and programs for preventing discriminatory practices and thus leadd to effective social inclusion of children with $\mathrm{CD}$. It was found that for social inclusion what is crucial is not the type of $\mathrm{CD}$, but whether the person has any $\mathrm{CD}$ at all.

\section{Socially inclusive and respectful to the personal development programs for the prevention of discriminatory practices in relation to children with $\mathrm{CD}$}

According to Brenda Gannon and Brian Nolan, social inclusion means that the individual is able to participate fully in the life of the society in which he or she lives. Conversely, social exclusion raises an inability to do so. People with $\mathrm{CD}$ or disabilities, especially 
children, face multiple barriers to their full inclusion and thus they also face an increased risk of social exclusion in different dimensions (13). In terms of the social inclusion of children and adolescents of school age who suffer from CD, Brook and Galili indicate that they are the intersection of the health system and the system of education. It is, therefore, possible for them to not be integrated, creating a deficiency in one of the sectors, usually education, as health is a priority. The lack of communication between these two sectors and the lack of knowledge on the part of the teachers and educators are the main educational constraints for these students, which prevent to a large extent their social inclusion. (7)

The process of social inclusion also accumulates the so-called problem solving, coping strategies, which are used for concrete actions aiming at overcoming the stressors that are also specific to a disease. Social inclusion is achieved when children and youth are not as different from their healthy peers, when they have established practice for their treatment and the care for themselves. Inclusion is indicated by the formation of a cognitive scheme, through which the child starts to interpret his or her experiences with the disease as something natural and familiar (4).

Sunny Im-wang and team reported that for social inclusion, no matter on which stage of the development of social skills it will focus, school is crucial. What happens during the school day is transferred to the time spent at home, which can dictate the behaviour of the children. According to the cited author's team, as a whole, children with $\mathrm{CD}$ are at greater risk of meeting difficulties in their social inclusion, in comparison to healthy children (14).

The lack of information on the part of the teachers and understanding of the impact of $\mathrm{CD}$ on childhood is a common problem which can lead to inaccurate assessments of the child's symptoms and inaccurate assessments of its educational and social skills (15). Therefore, there is a general consensus that the spreading of information among teachers, combined with an open communication between parents, the medical team and the school staff are needed to enhance the positive adaptation of chronically ill children in the classroom. Educators and teachers are among the group of professionals responsible for ensuring the quality of the life experience of students living with chronic diseases. Schools are facing challenges, including children with various diseases in the classroom (16).
Most children spend almost half of their waking hours with their teachers and school staff. However, most teachers have had training which is insufficient for the needs of children with disorders in the classroom. Nowadays, teachers are mainly familiar with the specifics of children with SEN, but not with the specificities and characteristics of children with $\mathrm{CD}$. Instead of placing the students in special educational programs for children with learning disabilities and mental retardation, schools should rather think differently about children with $\mathrm{CD}$, through the development of programs for those children who integrate their health and educational needs, noted Irwin and Elam (16).

With limited knowledge and resources, teachers and administrators could not respond to the serious health episodes with some improvised plans. Inadvertently, they can create educational barriers and eliminate the possibility of a reasonable educational experience of students with a disease, some authors reported. Many children with $\mathrm{CD}$ do not immediately fit into the predetermined programs in schools. Even when these children return to the classroom after hospitalization, rehabilitation, etc., the lack of knowledge of the educational implications of the disease for the child on the part of the teacher creates additional challenges in the educational process.

Researchers have concluded that chronic physical diseases are associated with reduced self-esteem. Confidence grows with positive experiences, people who work with children with $C D$ should encourage the attempts at success and positive peer relations, which are an important source of self-esteem. In addition, special prevention and intervention programs aimed at providing real information about $\mathrm{CD}$, increasing the social competence and reformulation of stressors have been found to enhance the self-esteem of children and adolescents with $\mathrm{CD}(17,18,11,19)$.

Wideman-Johnston (2011), indicates that the integration of pupils with $\mathrm{CD}$ in mainstream schools enables them to participate in the community. The fact that they attend school provides many more benefits than just their educational development. Consistent school attendance provides opportunities for partnership, support and enhancement of the self-worth of the individual(9). Taina Maues supports the view that consideration of the needs of students with $\mathrm{CD}$, inclusion in conventional life experience by attending a 
mainstream school is beneficial for students with $\mathrm{CD}(4)$.

In order to strengthen the achievements of students with $\mathrm{CD}$, educators and teachers should provide students with learning opportunities that are relevant to their lives. Offering students the opportunity to improve communication, engage in problem solving, critical thinking, conflict resolution and use coping mechanisms are not only necessary for functioning in society, but also for dealing with the chronic condition. It is clear that often the everyday life of children with $C D$ is filled with medical procedures, medications, doctor and hospital appointments, diets. Therefore, the support and understanding of the teacher is of the utmost importance in the educational process of chronically ill children.

In support of students in these situations, teachers can help the children's resources, allowing them to develop their skills and encouraging them to create relationships with other students with $\mathrm{CD}$, through maximum cooperation and a sense of belonging to a community. Without creating favourable conditions for students with $\mathrm{CD}$, the school environment can quickly become a place where they are struggling with the learning progress, partner relationships and psychological setbacks. Hamlet et al (2011) argue that the overall education of a child with $\mathrm{CD}$ consists in this, that it be provided with the educational community that has resources and personnel that can meet their educational, social, emotional and physical needs (20).

To facilitate the work of teachers in mainstream schools, foreign authors offer brief information packages for each of the most common CD. Each packet must contain a clear and concise description of the disease and its manifestations, including common medications and treatments and their side effects, as well as a prognosis of the disease. The package should also include information on education and the social complications, along with tips on training and interaction with chronically ill students. In the information package there should also be a list of resources, including organizations and materials that teachers and students can use to increase their knowledge and understanding. Teachers, school staff, psychologists, and all who are in contact with a student with $\mathrm{CD}$ should receive the respective appropriate package. In addition, a series of round tables, seminars, workshops or forums for dealing with the most common CDs should be held. In each case, medical and other health professionals, parents of sick children and a teacher or other persons with experience in education should be included. In most cases, it is recommended to include a student or an adult with the disease, which is the topic of the roundtable, seminar, training or forum.

Instead of a conclusion: the risk of discrimination of children and pupils without $C D$ when the school environment has to integrate children with $C D$

School children who are without CD and interact with children with chronic diseases have not been studied enough in the scientific literature. In view of the data presented here, it should be concluded that the children without CD would exhibit specifics in their behaviour, development and social functioning in the presence of a child with a chronic illness in their class. They also fall into a situation of social inclusion through the mechanism of adaptation to the $\mathrm{CD}$ of a child. It is necessary to pay particular attention to this group of children, as stressors for them in the presence of such a situation are also not few, especially if they are not well informed and mentally prepared. When a child with asthma receives an asthma attack during the lesson, the stress from the incident could cause serious damage to the emotional state of children without CD. Hannah and Midlarsky reported that growing up with a sick relative in the family has positive sides, such as developing a greater sense of empathy and compassion, for example. This statement could similarly be correlated to children without $\mathrm{CD}$ when they are in a general school environment with a child with CD (21).

In order for the training of students with $\mathrm{CD}$ to be adequate, the teachers must be familiar with the specifics of these children, as well as the emotional relationship between them and their peers, but also with the changes in the behavioural patterns of their peers.

\section{REFERENCES}

1. Steven R. Shaw, Sarah E. Glaser, Melissa Stern, Corina Sferdenschi, and Paul C. McCabe,Responding to Students' Chronic Illnesses, USA, 2010.

2. Buyuklieva E., The point of "tolerance" between teachers and parents of children with chronic illnesses, 2014.

3. Brandi Hainault, Educating children. Educating children with chronic illnesses 2013, (p.6).

4. Tainá Maués Pelúcio Pizzignacco, Regina Aparecida Garcia de Lima, Socialization of children and adolescents with cystic fibrosis: support for nursing care, University of Sao Paulo, 2006. 
5. Anfenson M. The school-age child with cystic fibrosis. J Sch Heath 1980;26-8

6. Anders JC. Crescer como transplantado de medula óssea: repercussões na qualidade de vida de crianças e adolescentes. Rev Latino Am Enfermagem, 2004.

7. Brook U, Galili A. Knowledge and attitudes of high school teachers towards pupils suffering from chronic disease. Patient Educ Couns 2001.

8. Parker R, Aggleton P. Estigma, discriminação e AIDS. Cidadania e Direitos - Associação Brasileira Interdisciplinar em AIDS. Rio de Janeiro (RJ), 2001.

9. Gjengendal E, Rustøen $\mathrm{T}$, Walh $\mathrm{A}$, Hanestad BR. Growing up and living with cystic fibrosis. ANS Adv Nurs Sci, 2003.

10.Wideman-Johnston, T. Resilience and students with chronic illness: a literature review of fostering resilience into the lives of students with chronic illness. Journal of Educational and Development Psychology, 2011. (127-132).

11.Pao, M. \& Ludi, E. Psychosomatic symptoms in children with chronic medical illness; understanding pediatric psychopharmacology in the context of medical illness. Psychiatric Times, 2011.

12.Sentenac, M., Arnaud, C., Gavin, A., Moicho, M., Gabhainn, S. N., Godeau, E. Peer victimization among school-aged children with chronic conditions. Oxford University, 2011. (120-128).
13.Gannon, N. and B. Nolan, Disability and Social Inclusion in Ireland, 2009.

14. Sunny Im-wang, Kimberly Erlich, Mary Crittenden, Marianne Doyle, laura Julian, Jonathan Strober, Emmanuelle Waubant, A GuIde foR pARentS wIth A chIld oR teen IIvInG wIth MS, San Fransisco 2011.

15.Clay, D., Cortina, S., Harper, D., Cocco, K.M., Drotar, D. Schoolteachers' experiences with childhood chronic illness. Children's Health Care, 2004.

16.Irwin, M.K., Elam, M. Are we leaving children with chronic illness behind? Cincinnati Children's Hospital Medical Center. 2011, (67-80).

17.Chesson, R. A., Chisholm, D., Zaw, W. Counseling children with chronic physical illness. Patient Education and Counseling, 2004.

18.Pinquart, M. Self-esteem of children and adolescents with chronic illness: a metaanalysis. Blackwell Publishing Ltd, Child: care, health and development, 2012 (153-161).

19.Sein, E.P. Chronic illness: the child and the family. Current Pediatrics, 2001.

20.Hamlet, H. S., Gergar, P. G., Schaefer, B. A. Students living with chronic illness: The school counselor's role. Professional School Counseling. 2011, 202-210.

21.Hannah ME, Midlarsky E. Siblings of the handicapped: A literature review for school psychologists. School Psychology Review, 1985. 